\title{
GCU
}

Glasgow Caledonian

University

University for the Common Good

\section{Exploring the transition from student to health professional by the first cohort of locally trained occupational therapists in Ghana}

Nkansah Opoku, Eric; van Niekerk, Lana; Jacobs-Nzuzi Khuabi, Lee-Ann

Published in:

Scandinavian Journal of Occupational Therapy

DOI:

10.1080/11038128.2020.1865448

Publication date:

2022

Document Version

Author accepted manuscript

Link to publication in ResearchOnline

Citation for published version (Harvard):

Nkansah Opoku, E, van Niekerk, L \& Jacobs-Nzuzi Khuabi, L-A 2022, 'Exploring the transition from student to health professional by the first cohort of locally trained occupational therapists in Ghana', Scandinavian Journal of Occupational Therapy, vol. 29, no. 1, pp. 46-57. https://doi.org/10.1080/11038128.2020.1865448

\section{General rights}

Copyright and moral rights for the publications made accessible in the public portal are retained by the authors and/or other copyright owners and it is a condition of accessing publications that users recognise and abide by the legal requirements associated with these rights.

Take down policy

If you believe that this document breaches copyright please view our takedown policy at https://edshare.gcu.ac.uk/id/eprint/5179 for details of how to contact us. 
Title: Exploring the transition from student to health professional by the first cohort of locally trained occupational therapists in Ghana.

\begin{abstract}
:
Introduction: The transition from student to occupational therapist for new graduates has been described as a period of extreme stress and anxiety; novice therapists enter a world that is new and complex upon starting clinical practice. The first locally-trained occupational therapists in Ghana worked autonomously and in a self-directed manner from their first year of practice in a country where occupational therapy had not been established. The study sought to explore the transition from student to clinician, made by the first cohort of locally trained occupational therapists in Ghana.
\end{abstract}

Methods: An interpretive phenomenology approach was used to explore participants' experiences of their transition from occupational therapy students to clinicians in Ghana. Six participants were selected using purposive, maximum variation, sampling. Data were collected by means of in-depth interviews and analysed using an iterative, inductive approach.

Results: Four themes emerged: Being "new" in a new profession, Introducing occupational therapy into a new environment, Personal and professional competence, and "The future is bright”. New graduates found continued professional development activities, such as additional reading, seminars and conferences, essential for successful transition into practice.

Conclusion: The importance of supervision and mentorship was highlighted in the study. Explicit attention to factors that support assimilation of new graduates within health care facilities were highlighted. The importance of continued professional development in development of practice competencies was foregrounded. Strategies to facilitate multiprofessional work were demonstrated. 
Keywords: Career adjustment, Clinical practice, Clinical supervision, Interpretive phenomenological analysis, Mentorship, Novice health professional, New graduate, Occupational therapy, Supervision.

\section{INTRODUCTION:}

The absence of occupational therapy services in Ghana's health care system over the years created a gap in healthcare delivery and restricted the holistic approach to healthcare delivery [1]. Historically, occupational therapy services were only offered in psychiatric hospitals by occupational therapy assistants who received in-service training in the 1980s. The first occupational therapy education programme in West Africa commenced in 2012, the result of a collaboration between the Ghanaian Ministry of Health (MOH) and the University of Ghana $[1]$.

The four-year undergraduate programme, accredited by the World Federation of Occupational Therapists, comprises both theoretical and practical components with clinical placements (fieldwork) forming the main practical component of the programme In an ideal situation, occupational therapy students would be supervised by occupational therapists during clinical practice [2], however, in the absence of occupational therapists, supervision was provided remotely by occupational therapy tutors employed at the University of Ghana. On-site supervision was provided by other health professionals including Physiotherapists and Nurses. [1].

The first cohort of occupational therapy students in Ghana comprised eighteen students; they graduated in 2016 with a Bachelor of Science in Occupational Therapy. This group transitioned 
from being students to health professionals working in a health system that did not have the occupational therapists' services before. Exploring the experiences of this cohort thus provided a unique opportunity for education research as they worked autonomously and in a selfdirected manner from their first year of practice in a country that was new to the services of occupational therapists [1].

A range of factors influence the transition of new graduate health professionals into practice. A comprehensive integrative review exploring the transition for new graduates of all health professionals into practice was done [3,4]. The barriers, facilitators and coping strategies of transition into practice among new health graduates were shown to be affected by systems and structures, personal capacities, professional competence and mediating processes, which included learning as an ongoing process, establishing supportive contacts, asking for help, and effective time management [4]. In this article the authors focus on occupational therapy-related literature on the transition from student to health professional. A review of occupational therapy literature showed students' clinical placements to be an important determinant of the success of their transition into practice upon graduation [5]. Clinical placements enable students to develop a foundation for practice and expose them to the clinical practice world [5]. New graduate occupational therapists' transition from student to clinician has been described as a period of extreme stress and anxiety [6] because they enter a world that is different and complex upon starting clinical practice [7].

Two Canadian phenomenological studies, one exploring the lived experience of rehabilitation students $(n=6)$ during their final placement and first year of practice and the other exploring the experiences of new graduate occupational therapists $(n=6)$ during their first year of practice [5], illustrated various demanding aspects of the transition. Toal-Sullivan [5] showed that transition into practice can be marked by intense feeling of shock, extending across all areas of professional competencies and even personal lives. Also, new graduate occupational therapists 
experienced challenges with transferring knowledge acquired in the classroom to practice contexts because of the perceived gap between knowledge acquired as students and that required in practice [5]. Similarly, Tryssennaar and Perkins [6] found that new graduates believed they lacked practical knowledge and techniques required for practice, as they expressed concerns about their competence.

When new graduate occupational therapists' ability to identify their roles in the team of health professionals they work with was explored, they were found to experience difficulty to differentiate their own roles from those of other health professions $[5,7,8]$. New occupational therapy graduates experienced moments of self-doubt and concerns about their competence due to difficulty identifying their roles [5,3]. Naidoo et al [7] conducted a qualitative case study among final year occupational therapy students in South Africa to explore their perception of preparedness for practice. The participants felt their undergraduate programme did not equip them with sufficient knowledge and practical skills for efficient occupational therapy practice.

The complex nature of the transition from student to health professional beckons new clinicians to develop their professional identity, a process that requires guidance and support [6]. Professional support has been identified in the literature as a significant strategy to ease the stress of transition into practice for new graduates [5,9]. Formal supervision by an experienced occupational therapist, who is capable of providing essential feedback and support, is considered a crucial component of a successful transition and central to the new graduate occupational therapists' perceived success at work [9,10]. Furthermore, guidance from an occupational therapy-specific supervisor enables new clinicians to develop clinical skills and strategies to overcome professional issues relating to client case work, management and organizational issues, professional development, as well as personal and emotional issues [4, $9,10]$. 
The complexity of transition into practice for new graduate occupational therapists suggests that making the transition from students to health professionals for the first cohort of the occupational therapy programme in Ghana, has been a challenging experience as Ghana did not have existing occupational therapy services provided by trained occupational therapists $[6,7]$. This group of new graduates did not have the opportunity to work under professionspecific direct supervision during their undergraduate fieldwork nor during their transition to practice [1].

This interpretive phenomenological study aimed to explore the experiences of the transition from student to health professional by the first cohort of locally trained occupational therapists in Ghana [12].

\section{MATERIALS AND METHODS}

\section{Design}

A qualitative interpretive phenomenology was used [12]. Interpretative phenomenology enables the exploration of experiences and their meaning for participants. It involves coconstruction of meaning through inductive reasoning [12]. The fundamental difference between descriptive and interpretive phenomenology is that in the latter, researchers do not attempt to remove themselves (their opinions and ideas) from the meaning they extract from the text [13]. Prior experiences of the researcher are not considered 'biases', instead, these are relied on to promote a greater understanding of the phenomenon of study [14]. The research participants and the researcher together make sense of the phenomenon of study; also known as 'intersubjective knowing' [15]. However, findings are presented in such a way as to ensure that quotes, observations and interpretations made are clearly attributed to either participants or researchers. In this study pseudonyms were used to link quotes to a particular participant;

additional observations and interpretations were made by the authors. The study was 
conducted by a Masters student (ENO) with the guidance of two supervisors with experience in qualitative research ( $\mathrm{LvN}$ and $\mathrm{LJNK})$.

\section{Study population, recruitment and sampling}

Recruitment commenced with mailing of information sheets to the first cohort of occupational therapists. Email addresses were obtained from the Occupational Therapy Association of Ghana. Twelve potential participants responded to the invitation to participate. Maximum variation sampling [16] was used to select six participants from the twelve potential participants. Participants were selected through purposive sampling for the relevance of their experiences to the phenomenon of interest. Six participants is considered sufficient when the researchers intend to explore detailed interpretive accounts of a phenomenon using in-depth interviewing [17].

\section{[Insert 'Table 1: Research participants' variation criteria here]}

Maximum variation was obtained for the three variation criteria shown in Table 1 . These were selected to illuminate the different aspects of the phenomenon of interest [16]. The principal author contacted selected participants, explained the study and answered questions before obtaining verbal consent and arranging the first interview with participants.

\section{Data Collection}

The position of the researcher in phenomenological study is of particular importance as it impacts on the relationship between the researcher and the participants. An "insider" researcher is one with characteristics, experiences, positions or roles that are the phenomenon of interest in a study [14]. The first author held an 'insider' perspective by virtue of being in the first cohort himself. 
Both the 'insider' and 'outsider' positions have potential advantages and disadvantages, with neither considered superior to the other [14] Potential benefits of being an "insider" researcher include being viewed by the participants as more 'alike'. The insider researcher has already established community links with study participants thus promoting the establishment of rapport and enabling reciprocity. It is also reported that, participants are more likely to open up when interviewed by an insider. Furthermore, insider researchers are considered to have tacit knowledge as a result of their familiarity with the research participants which can deepen understanding. The objectivity, authenticity and reflexivity of the research is increased because the researcher is close to the research project [14]. In this study care was taken during the process of negotiating informed consent to protect potential participants' autonomy in decisions whether or not to participate in the study with details on the process provided for ethical considerations.

In-depth interviews were used to elicit rich and detailed accounts of the participants' experiences $[11,13]$. The first author conducted two face-to-face, in-depth interviews with each participant, each lasting an average of one hour. Written informed consent and a participant's personal information was obtained prior to the commencement of the first interview.

The interview took place at a time and place that was convenient for each participant and allowed for confidentiality to be maintained. Interviews were conducted in English and guided by the question, "Tell me what it was like for you to adjust from being a student to being an occupational therapist?". The second interview was conducted after transcribing and analyzing the first interview (see data analysis). During the second interview, the researcher discussed the provisional findings from the first interview with each participant. The participants had the opportunity to confirm the interpretations, elaborate further and add depth of understanding. All interviews were audio-recorded and in addition field notes were made. Data saturation was evident by the end of the fourth interview. That is, the themes derived from the fifth and sixth 
interviews reinforced already identified themes but did not identify any new information. A total of 15 hours of data collection was completed. Participants participated comfortably, with no signs of discomfort, awkwardness or avoidance of subjects. Information on trustworthiness and rigour has been provided later in this paper.

\section{Data Analysis}

The researchers adopted an inductive and iterative approach to data analysis [18]. All interviews were audiotaped and transcribed verbatim. Coding was first done by ENO, discussed, reviewed and refined together by all three authors. Analysis followed each interview prior to the next interview in such a way that, data analysis occurred alongside data collection. This enabled the researcher to identify common themes and to expand the discussion where appropriate, during the next interview [17].

In interpretive phenomenology, it is recommended that researchers immerse themselves in the data to understand the meaning participants make of their experiences [17]. ENO repeatedly listened to the recordings, read and reread the transcripts to familiarise himself with the accounts of the participants. He recorded observations and captured his reflections on the interview process by writing notes. Any thoughts or comments of potential significance were captured as notes during the initial analysis of interviews, which took the form of inductive content analysis. Subsequent interpretive comments were made, drawing the experiences of individual participants together while highlighting distinctive phrases and emotional responses. The researchers collectively ensured that interpretive notes were detailed, comprehensive and reflected participants' experiences. Notes that were kept throughout the process informed the emerging categories. Similar categories were grouped together into themes, then, common themes were grouped into overarching themes. Themes were thus developed to portray how the participants were making sense of their transition from student to practice. [19]. Four themes emerged that will be detailed in the findings section. 


\section{Trustworthiness and Rigour}

The different aspects of trustworthiness and rigour as proposed by Lincoln and Guba [20] were ensured in the study. Strategies including member checking, reflective journaling, detailed field notes, data source triangulation and peer debriefing with two experienced qualitative researchers were used to ensure trustworthiness and rigour. Member checking was performed with each participant to ensure the researcher had accurately captured participants' experiences in the research findings [21]. Participants were in agreement with the summary of the findings, thus ensuring internal validity. To ensure rigour and credibility, the researcher kept a reflective diary of the research journey which was updated after every contact session with a participant or after any session of working with the data. Detailed field notes were taken before and after each interview to reduce potential researcher biases [21]. Triangulation of data was achieved through using in-depth interviews, field notes and reflective diaries [20]. Maximum variation sampling approach ensured as wide a variety of information was included as was possible within the parameters of this study [16]. Additionally, peer debriefing was done through regular contact sessions with two researchers who are experienced in qualitative research. This ensured consistency in the development and interpretation of themes and codes, thereby strengthening the reliability of the results [21]. The study was conducted by a Masters student (ENO) with the guidance of two supervisors who are experienced qualitative researchers ( $\mathrm{LvN}$ and LJNK).

\section{Ethical considerations}

Ethical approval was obtained from the Health Research Ethics Committee of Stellenbosch University (HREC1-2019-9536). Prior to obtaining written consent, each participant was given information explaining the research including reasons for conducting the study, goals of the researchers, interviewer characteristics and how confidentiality and de-identification would be maintained, through the use of pseudonyms and the use of password protected computers. Care 
was taken to assure participants that they were free to decline participation and that withdrawal of their participation at any stage would not elicit negative reactions or consequences. Electronic data (including interview recordings and transcriptions and all other forms of electronic data generated by the study) was stored on the authors' password protected personal computers, external hard drives as well as on a virtual drive. Hard copies of signed informed consent forms as well as any other documents containing participant information was locked in a steel cabinet. The authors did not link the pseudonyms of participants to their practice setting or specialisation areas in order to protect confidentiality, given the relative small number of the first cohort of occupational therapists in Ghana.

\section{FINDINGS}

The following four themes emerged from the data: 1. Being "new" in a new profession 2. Introducing occupational therapy into a new environment 3. Personal and professional competence, and 4. "The future is bright". (See Table 2).

\section{[Insert 'Table 2: Themes and Sub-themes' here]}

\section{i. Being "new" in a new profession}

The theme "being new in a new profession" reflected participants' description of their transition, personal capacities and professional competencies as a result of being new graduates in a profession that was new in Ghana. All the participants alluded to what they perceived as a 
disparity between their educational programme and the realities of practice. They described these as two different worlds. The application of some theoretical knowledge learnt while they were students was not immediately obvious. One of the participants stated,

“... they are two totally different worlds... What I learnt [as occupational therapy student] seemed not to be applicable in the setting that I was in, and it appeared all that I did [in education programme] was theory and now I am on the field and expected to do hands-on things, but I didn't know what to do." (Adjumma, first interview).

Participants felt ill-prepared for the demands of professional practice shown by the fact that the participants indicated a feeling of doubt and uncertainty at the initial stages of work. They needed to comprehend their full role as occupational therapist in the practice context, which included working with clients and other health professionals; this was experienced as very different from being a student. Because independent professional practice encompassed much more than the requirements they had to meet as occupational therapy students, they often felt as if they 'did not know anything', which impacted negatively on their confidence levels. One participant stated,

"Initially, I was not confident because I didn't know what occupational therapy was myself - even though I'd spent four years in school. I just didn't know what I was doing out there. My four years in school did not really prepare me for the field. It was more of theory and they didn't tell me I had to survive on my own." (Aliyah, first interview).

Participants' feelings of uncertainty and fluctuating levels of confidence stood in contrast with clients and fellow health professionals' perceptions that they were experts. All participants, except one reported the perceived expectation for them to know what to do and how to manage all tasks associated with their roles as occupational therapists and members of the 
interdisciplinary team; expectations the participants felt were unattainable. Amidst these anxieties, participants felt compelled to prove themselves and to defend their profession.

"I didn't know what was expected of me in my setting...I knew they were expecting me to do much, but as to what exactly those expectations were, I couldn't tell. They also saw me as expert ... they were like wow! Occupational therapist? ...they knew that there were only eighteen locally-trained occupational therapists in Ghana and West Africa, and they were fortunate to have one of them." (Adjumma, first interview)

Another participant stated:

"I don't know but for some reasons they had so much confidence in me ... They knew I have been to a university and I have a degree in occupational therapy so I should know a lot ... And I didn't want to disappoint them" (Ayison, first interview)

Participants reflected on their initial inexperience with regret when they perceived their competencies to have impacted negatively on service delivery:

"Sometimes I pray I get the opportunity to meet the clients I met in my first year to correct my mistakes...to right my wrongs...honestly... (participant sighs) ...sorry I am getting emotional now" (Adjumma, first interview)

During their transition participants experienced themselves as "trying out new skills" as they were not yet sure their interventions would work:

"I was just doing trial and error ... if I try and it doesn't work, then I know that next time I don't have to take that path" (Abena, first interview).

Another participant stated: 
"It actually feels like you are doing something that you have no knowledge on...you've not seen anyone practice it before" (Adjumma, first interview)

Some participants indicated that clients and other health professionals were uncertain of their roles as occupational therapists. They emphasized that they had to educate fellow health professionals, clients and administrative staff on their roles as occupational therapists.

“Other health professionals didn't know my role...they only attributed occupational therapy to craft work...so I had to go around every ward to do a presentation on what occupational therapy is about" (Abena, first interview)

Because there were no established occupational therapy departments or occupational therapy practitioners in the country, participants started their professional careers without the benefit of being supervised by experienced occupational therapists; this was a critically challenging experience for the participants. Some participants stated that they were supervised by other health professionals who lacked knowledge of the role of occupational therapists.

“there was no supervisor...I was only reporting to a physician assistant who didn't also know what occupational therapy is" (Adjumma, first interview).

Aspects of work with fellow health professionals was experienced as challenging for some participants, particularly in contexts where they perceived that physiotherapists were fulfilling the role of occupational therapists. Some participants shared their opinion that physiotherapists felt threatened by the new appointments of occupational therapists in certain settings.

"Before I was posted to my setting, physiotherapists were made to assess ADL functioning using Barthel index... ADL assessment was given to me after my presentation on occupational therapy roles...the physiotherapists were not happy about 
it and they threaten to take back that role...they feared occupational therapists might be a replacement of their services." (Anyanah, first interview).

Participants highlighted situations during their transition where they felt belittled as they were not accorded the expected respect and recognition.

"sometimes they talk to me as if I am one of the orderlies...they don't accord any respect...they thought I was just someone who had learnt some vocational skills and have come to teach the patients" (Abena, first interview).

Some experienced situations where other health professionals made them feel their services as occupational therapists were not needed in the practice setting:

“...Even after presenting on occupational therapy roles, they ask you questions trying to imply that you are really not needed here... we are already doing all the things you've talk about...or we can do without them...besides we don't even have a space for you". (Aliyah, first interview).

Some also expressed instances where they felt inferior because they were young:

"They tell you they are older than you and you just graduated into the system hence you should obey their every command" (Ayison, first interview).

\section{ii. Introducing occupational therapy into a new environment.}

This theme reflected participants' experiences with the systems, protocols and the structures of their workplaces and the relationship with other healthcare staff as they strived to establish occupational therapy services in a new environment. 
All the participants indicated that there were no support strategies at their workplace to integrate new graduates into the system. Participants' experiences were similar to what Seah et al [22] described as "being thrown in the deep and having to either sink or swim".

"There was no strategy to integrate us into the facility... not even orientation... we had to help ourselves to fit in" (Aliyah, first interview)

Some participants highlighted that, because of systemic barriers to addressing individual staff concerns at their workplaces, it took a long time for their concerns to be addressed. Others also found it confusing and frustrating working within the system.

“When I started work, there wasn't any structured protocol...it was very confusing and frustrating working with the system...there wasn't any proper structure in the hospital...it was so disorganized...so it was a big headache for me" (Abena, first interview).

In contrast, other participants reported that their concerns were completely overlooked, and they were discouraged from changing the status quo.

"When I report any issue to my superior, he tells me to forget about it...he even discourages me...he tells me to find a corner and sit... and shouldn't find any trouble for myself'. (Agyeman, First interview)

All participants, except one, discussed that the leadership of their health facilities were more interested in "acute symptom relief" services for patients rather than rehabilitation. They believed that leadership preferences for medical model healthcare made it difficult to establish occupational therapy services in those health facilities.

"The management of my facility were only concerned about cure for patients...they didn't understand rehabilitation... and so they didn't know the members that make up a 
rehabilitation team... so they didn't see the need to give us a space”. (Adjumma, First interview)

Participants stated that lack of space and equipment to start occupational therapy services was a major challenge to their transition, they resorted to bed-side and home therapies which limited their potential.

"There was no space for occupational therapy...therapy was usually done by the patients' bedsides...which actually limited me” (Anyanah, first interview)

Another participant stated:

"Sometimes you'll know the person needs your help... you know you can do something...but you can't even get the equipment to help the person with" (Aliyah, first interview)

Participants discussed efforts to educate fellow health professionals, clients and administrative staff on the role of occupational therapy.

"At a point, I had to lobby to do a presentation on occupational therapy roles...I made clear what my roles were...that was one way I dealt with all the conflicts that were going on" (Agyeman, second interview).

Another participant stated:

“...always had to explain what occupational therapy is everyday...always...always telling people that you are not a physiotherapist but an occupational therapist”. (Aliyah, first interview)

Participants discussed experiences of having to explain their roles each time they introduced themselves as occupational therapists. One participant stated: 
"Sometimes I get tired of having to explain my role all the time...okay so what do you do?... and I'm like...I'm an OT just like PT' (Adjumma, first interview).

Having to source funds required to support their occupational therapy activities was another aspect participants highlighted:

"OT activities demands a lot of money which management were not ready to give...I had to write a lot of proposals to companies to solicit for funds and all that" (Abena, second interview).

Some participants urged other health professionals to be receptive of new graduates and endeavour to learn about the role of occupational therapy.

"They should not be hostile to new OTs...they should look at OTs as one key health professional who puts the icing on the cake...to make patients functional and then live good and satisfying lives...they should not resist what OTs are coming on board with" (Anyanah, Second interview).

Some participants experienced intraprofessional conflicts as the occupational therapy assistants who were already in the system felt threatened:

“...So they had to do everything in their power to limit me...so they will oppose everything I want to put in place just to suppress me... as a newly qualified OT, I had so much enthusiasm...so there was always that kind of friction" (Abena, First interview)

\section{iii. Personal and professional development}


This theme reflected participants' experiences of ensuring continued professional development as well as recommendations to improve the level of professional competence of occupational therapy in Ghana.

Participants appreciated the need to develop both professionally and personally. All participants highlighted the use of both formal and informal avenues to ensure continued professional development. All participants indicated their reliance on personal reading and research:

“Assessment was an issue...I hadn't seen an OT actually assess a client fully for me to know that okay, this is how it is done... most of it was what I had read from books that I try to implement" (Anyanah, first interview)

Another participant stated:

"I resorted to reading all the time...I had to read and read and read and also go online to search and watch YouTube videos" (Adjumma, first interview)

All participants indicated attending conferences, workshops and training to improve their competence.

“Am always interested in workshops and conferences because I feel like I don't know anything...so whenever I hear of workshops, I am interested”. (Aliyah, second interview)

Some participants learnt from other health professionals, especially physiotherapists.

"I learnt from the physios because most of the things they do, we are supposed to do them ...so I ask them why they do it...get the rationale and then learn from them". (Ayison, first interview) 
Some participants were fortunate to have experienced occupational therapists from other countries as mentors whom they sought advice and guidance from.

"I encountered an occupational therapist from Australia who became my mentor...so I would contact her if I had any challenge...then she will reply...that was how I survived within the first year". (Adjumma, first interview).

Some participants identified a positive attitude towards learning as a start to professional competence.

"I always made up my mind to open up and be willing to learn all the time...I was ready to accept criticism”. (Agyeman, first interview).

Learning from their own mistakes was considered an essential step towards improved competence and confidence:

"I feel low-spirited when I think I am not doing something right... at the end of the day, I go home and try and think...ow! What could I have done about that differently?" (Abena, first interview)

Readiness and ability to adapt was considered important:

“...there is a more challenging world compared to the classroom ...you will realise therapy doesn't always go as you expect it to...you should be ready to adapt to these realities". (Ayison, second interview).

All the participants identified limitations in the occupational therapy undergraduate curriculum and called for changes.

"Our curriculum should be changed ...it should be more practical-based...practical case scenarios...even if it involves going on ward-rounds with students like the 
medical students do...we should be concerned about these things not theory theory theory...some of the courses should be scrapped because I didn't see the need" (Adjumma, first interview)

Another participant stated:

"the courses have very good names but the problem is with the course content...A lot has to be done to the curriculum to ensure that when students are done with school, they will have basic clinical skills...like clinical assessment and interventions...even therapeutic communication" (Anyanah, first interview)

Others advised that clinical examination should be more attuned to practical application:

“Clinical examination should be a measure of the students' clinical skills not another measure of their theoretical knowledge" (Agyeman, first interview)

“...the logbooks should be a record of the cases they saw... what they assessed and what interventions they gave...this will help them reflect more on the important things...not the theoretical knowledge about the values and principles of the OT profession" (Anyanah, first interview)

\section{iv. "The future is bright"}

One of the questions used to collect data was asked to elicit participants' expectations of the occupational therapy profession in Ghana in the future. Participants generally held an optimistic view of the profession's future and expressed hope that occupational therapy will thrive. Participants' hopeful aspirations for occupational therapy were captured in this theme; 
their optimism was for the future, thus situating current challenges they were experiencing part of the process of a profession establishing itself for the first time..

"the ultimate is that, in spite of all the challenges, we are trying hard to be given the recognition we deserve in our health system...we should still move on and focus...one day it will work out for us" (Ayison, second interview).

Participants expect occupational therapy in Ghana will have a strong contextually relevant research foundation coupled with evidence-based clinical practice.

"I expect OT in Ghana to be big!...having a strong foundation of research that are relevant to our context...that can inform our practice here in Ghana...you know...evidence-based practice I believe is the foundation to succeed as a health profession”. (Agyeman, second interview)

All, except for one participant, discussed that they expect occupational therapy departments to be in every hospital in Ghana.

"I expect that OT will be accepted in each and every hospital... that most of the hospitals will embrace OT and see it for the important profession it is" (Anyanah, second interview)

All the participants expressed their expectation that occupational therapy will be well known in Ghana.

"I am looking forward to some years where OT will be a household name...like you meet people and they will be like... oh! I was in this setting and an OT helped me do this or that or for a relative of mine or my child...yes!...I pray we get there...people will encounter us and they will see positive results...yes!...very very soon” (Adjumma, second interview) 
Another participant also stated:

"we should have a lot of OT centers in most of the hospitals...we should be in the industries...in the ministry of health...out there in the institutions where we have to be...we are a broad profession and with the right people supporting us, I think we will go far” (Abena, second interview).

\section{DISCUSSION OF FINDINGS}

The aim of the study was to explore the experiences of transition from student to clinician by the first cohort of locally trained occupational therapists in Ghana. Themes identified were consistent across all participants.

The findings revealed moments of self-doubt uncertainty and concerns about competencies and level of preparedness for practice. Similar to Toal-Sullivan's findings, the factors contributing to successful transition included new graduates' confidence in their knowledge and skills [5]. Consistent with the literature, participants placed emphasis on the positive influence that practical experiences have on new graduates' sense of competence during the transition into practice $[3,5]$. They recommended that the practical experiences of students should be enhanced through practical demonstrations, case studies and clinical fieldwork experiences, to expose students to the world of practice and enable them to develop a firmer professional foundation before starting practice. Practical exposure within the university curriculum has been found to provide new graduates with practical skills and confidence to know what to do in the field, thus making transition into practice less stressful $[3,18]$.

Participants shared their difficulties practicing occupational therapy when they barely understood what the profession was themselves. They felt they were not adequately prepared 
for practice and highlighted the challenge of having to practice independently without supervision. This is consistent with findings by Hunt and Kennedy-Jones [11] highlighting that supervision helps new graduates to develop their professional identities and improve their overall perceived success in the work context. In the same study, a lack of supervision was identified as a critical factor that made the new graduates' transition more challenging. Robertson and Griffiths [23] similarly emphasised that supervision assisted new occupational therapy graduates to make the right decisions and to develop confidence in the field.

Assimilating into the workplace was a source of great stress for participants. This was confounded by the absence of orientation and induction programmes, confusing workplace leadership structures, complex bureaucratic processes and superiors' lack of knowledge regarding occupational therapy.

Participants perceived the expectations placed on them as new graduates to be unrealistically high, thus contributing to their anxiety. They sought recognition and endorsement from other health professionals and clients, which meant they placed a high value on feedback received. This was similar to findings showing how validation from clients and other health professionals is important for augmenting new graduates' self-worth [22].

Delineation of roles between health professionals was complicated by overlapping responsibilities, specifically with physiotherapists. This finding might have been accentuated by occupational therapy's introduction into an existing health system in which other professions would have taken on important functions that usually fit within the scope of occupational therapy. The finding should be contextualized with recognition of the critical importance of meaningful collaboration between new graduates and other health professionals in the development of knowledge, skills, teamwork through interdependence [5]. 
Participants reported that lack of infrastructure (i.e. insufficient space and equipment) impacted on their ability to render optimal occupational therapy services at health facilities. Services were restricted to the bedside or within patients' homes. Similarly, Lee and Mackenzie [9] reported that new graduates considered inadequacy of resources as problematic and improvising was a source of great stress for their transition.

Participants recognised the need for continued professional development through attending conferences, workshops, training, personal reading, seeking support from mentors and other health professionals. This finding is consistent with literature emphasising continued professional development activities as essential for new graduates transition into practice $[3,5,7,11]$.

Finally, participants made recommendations for modification to their education programme to include more practical experiences to help the development of skills required for practice. This is consistent with findings from Tryssenaar [24].

Despite the many challenges participants experienced in their transition from student to occupational therapist, participants maintained a compelling sense of enthusiasm to establish occupational therapy services in Ghana. Participants' expectations for occupational therapy in Ghana were positive, believing that the profession will thrive. The authors are of the opinion that, participants' hopeful aspirations and their approach during the transition highlighted their strong belief in the potential of occupational therapy in Ghana; they seem equipped to deal with the challenges associated with establishing the profession in the country. 


\section{CONCLUSION AND RECOMMENDATIONS}

This study employed an interpretive phenomenological approach to explore the transition from students to clinicians by the first cohort of locally trained occupational therapists in Ghana. The themes that emerged elucidated the challenges of being 'new in a new profession'. New graduates encountered barriers to introducing occupational therapy into a health system for the first time. The study also confirmed the value and importance of continued professional development as a strategy to obtain and confirm practice competencies required by novice practitioners.

Findings from the study can inform curriculum development, clinical supervision, and mechanisms through which new graduates' transition into practice can be supported. The findings inform preparations for new education programmes and introducing occupational therapy in contexts withlimited professional support and supervision.

Ghana, currently the only country in West Africa, and one of the few countries in Africa with an accredited occupational therapy programme, could be seen as a case study informing developments in occupational therapy education and practice in similar contexts. There is the possibility that the findings might elucidate aspects of the transition from student to clinician that might have value in other countries with well-established occupational therapy professions as well. A continued focus on narrowing the potential gap between educational programmes and practice settings is advised. The study confirmed that new graduates value skills required for practice, such as assessment skills, communication skills, management and organizational skills, time-management skills and clinical decision-making skills. Furthermore, occupational therapy education should enable students to have a deep understanding of the profession's philosophies, knowledge and skills [22]. 
The importance of programmes to orientate and induct new graduates into their practice settings were illustrated and are thus recommended. Such programmes should focus on informing new graduates on the leadership structures, systems and processes in a format that is detailed, comprehensible and easily accessible. Within practice settings recognition of the contribution of occupational therapists as rehabilitation professional may smooth the transition from student to health professional and improve their confidence [23,24]. Accessible channels of communication for novice practitioners to voice their concerns is required to empower new graduates.

Expectations that new graduates should already possess all clinical competencies should be reduced. Both new graduates and existing health professionals should recognize learning as an ongoing process. Furthermore, it is important for new graduates to recognise that certain competencies can only be acquired during practice; an insight that might reduce anxiety during the transition.

A well-organized collaboration between university educators, and management of health facilities, is recommended to help new graduates to transition successfully into practice.

The first cohort of the occupational therapy programme can play an instrumental role in the education and training of subsequent cohorts by filling the supervision and mentoring gaps they themselves experienced. Opportunities and structures within which new graduates are supported to establish formal mentoring relationships with experienced occupational therapists in other countries should be considered. At the same time, the sharing of expertise and mutual learning between new graduates and students on clinical placements could be facilitated through peer-to-peer learning networks.

Future research should seek to explore other cohorts of graduates' experience of their student to clinician transition to identify if there are similarities or differences in their transitionary 
experience. This will provide a more comprehensive understanding of students transition into practice and generate more suggestions to optimize occupational therapy education and practice in Ghana.

\section{STRENGTHS AND LIMITATIONS}

It might have been easier to access the study participants because one of the authors was in the same cohort with the participants. Familiarity with the participants might have promoted the establishment of rapport and reciprocity during the interview. Open dialogue with participants resulted in in-depth data which promoted a greater understanding of participants' experiences of transition into practice. The researchers believe that, the objectivity, authenticity and reflexivity of the study was increased because the first author was in the same cohort as the participants [14].

A few potential limitations should be taken into consideration when interpreting the results. Even though some experiences might apply to other cohorts, findings are unique to the study participants and might not be transferable to other cohorts of occupational therapy students. Another limitation was that the study was retrospective as participants had to reflect on past experiences. A prospective study might better represent participants' experiences of transition as it is happening.

\section{ACKNOWLEDGEMENTS}

A special thank you is extended to the first cohort occupational therapists who participated in this research study, for sharing and helping us to understand their unique experiences of practising occupational therapy for the first time in Ghana.

Declaration of interest: The authors report no conflict of interest. 


\section{REFERENCES}

[1] Ndaa PO. Professional occupational therapy training in ghana: taking the initiative in the sub-region. 2014; Available from: www.academia.com.

[2] World Federation of Occupational Therapy. Minimum Standards for the Education of Occupational Therapists. Unpublished quality standards document, WFOT. 2016.

[3] Opoku EN. Exploring the transition from student to clinician by the first cohort of locally trained occupational therapists in Ghana. Stellenbosch University; 2020.

[4] Opoku EN, Niekerk L Van, Khuabi L-AJ-N. Exploring the factors that affect new graduates' transition from students to health professionals : a systematic integrative review protocol. BMJ Open. 2020;10:1-5.

[5] Toal-Sullivan D. New graduates' experiences of learning to practice occupational therapy. Br. J. Occup. Ther. 2006;69:513-524.

[6] Tryssenaar J, Perkins J. From student to therapist: Exploring the first year of practice. Am. J. Occup. Ther. 2001;55:19-27.

[7] Naidoo D, Wyk J Van, Joubert RN. Are final year occupational therapy students adequately prepared for clinical practice? A case study in KwaZulu-Natal. South African J. Occup. Ther. [Internet]. 2014;44.

[8] McCombie RP, Antanavage ME. Transitioning From Occupational Therapy Student To Practicing Occupational Therapist: First Year of Employment. Occup. Ther. Heal. Care [Internet]. 2017;31:126-142. Available from: https://doi.org/10.1080/07380577.2017.1307480.

[9] Lee S, Mackenzie L. Starting out in rural new south wales : the experiences of new 
graduate occupational therapists. Aust. J. Rural Heal. 2003;36-43.

[10] Hummell J, Koelmeyer L. New graduates: Perceptions of their first occupational therapy position. Br. J. Occup. Ther. 1999;62:351-358.

[11] Hunt K, Kennedy-Jones M. Novice occupational therapists' perceptions of readiness to undertake fieldwork supervision. Aust. Occup. Ther. J. 2010;57:394-400.

[12] Smith JA, Osborn M. Interpretative Phenomenological analysis In: JA Smith (ed) Qualitative Psychology. London: Sage,. London: Sage; 2003.

[13] Reiners MG. Understanding the Differences between Husserl's (Descriptive) and Heidegger's (Interpretive) Phenomenological Research. J. Nurs. Care. 2012;01:1-3.

[14] Blythe S, Wilkes L, Jackson D, et al. The challenges of being an insider in storytelling research. Nurse Res. 2013;21:8-12.

[15] Blackstone J. The empathic ground: intersubjectivity and nonduality in the psychotherapeutic process. State University of New York Press, Albany; 2007.

[16] Suri H. Purposeful Sampling in Qualitative Research Synthesis. Qual. Res. J. $2011 ; 11: 63-75$.

[17] Pietkiewicz I, Smith JA. A practical guide to using Interpretative Phenomenological Analysis in qualitative research psychology. Psychol. J. 2014;20:7-14.

[18] Smith JA, Osborn M. Interpretative phenomenological analysis as a useful methodology for research on the lived experience of pain. Br. J. Pain. 2015;9:41-42.

[19] Olive JL. Reflecting on the tensions between emic and etic perspectives in life history research: Lessons learned. Forum Qual. Soc. Res. 2014;15. 
[20] Lincoln YS, Guba EG. Naturalistic inquiry [Internet]. Beverly Hills, CA: Sage; 1985. Available from: https://library.city.ac.uk/record=b1100619.

[21] Krefting L. Rigor in Qualitative Rsearch: Assessment of Trustworthiness. Am. J. Occup. Ther. 2017;45:214-222.

[22] Seah CH, Mackenzie L, Gamble J. Transition of graduates of the Master of Occupational Therapy to practice. Aust. Occup. Ther. J. 2011;58:103-110.

[23] Robertson LJ, Griffiths S. Graduates' reflections on their preparation for practice. Br. J. Occup. Ther. 2009;72:125-132.

[24] Tryssenaar J. The Lived Experience of Becoming an Occupational . Therapist. Br. J. Occup. Ther. 1999;62.

[25] Hall P, Weaver L. Interdisciplinary education and teamwork : a long and winding road. Med. Educ. 2001;35:867-875.

[26] Koch L, Gitchel D, Kristin H. Preparing Students to Be Empathic interdisciplinary rehabilition team members. Rehabil. Educ. 2009;23:119-126(8). 


\section{TABLES WITH CAPTIONS}

Table 1: Research participants' variation criteria

\begin{tabular}{|l|c|c|}
\hline Male/Female & Practice Setting & Main Specialization Field(s) \\
\hline - Male & - Rural Faith-based Health Facility & - Paediatrics \\
& - Urban Public Health Facility & - Psychiatry \\
& - Urban Private Special School & - Community \\
& - Urban private Health Facility & - Adult Stroke \\
& - Rural Public Health Facility & - Orthopaedics \\
& \multicolumn{2}{|l}{} \\
\hline
\end{tabular}

Table 2: Themes and Sub-themes

\begin{tabular}{|l|l|}
\hline \multicolumn{1}{|c|}{ Themes } & \multicolumn{1}{|c|}{ Sub-themes } \\
\hline Being "new" in a new profession & Academic - practice disparity \\
\hline & Preparedness for practice \\
\hline & Interactions with clients \\
\hline "They saw me as expert" \\
\hline "Other health professionals didn't know my role" \\
\hline & Feeling belittled \\
\hline
\end{tabular}




\begin{tabular}{|l|l|}
\hline Introducing occupational therapy & Unavailability of support and feedback \\
\hline into a new environment. & Leadership and workplace protocols \\
\cline { 2 - 2 } & Educating others on OT roles \\
\hline & Lack of resources \\
\hline "Making things work" & Recommendations for other health professions \\
\hline Personal and professional & Recommendations for leadership and management \\
\hline development & Formal and informal learning \\
\hline & Trial and error \\
\hline "The future is bright" & Attitude towards learning \\
\hline & Recommendations for new graduates \\
\hline & Recommendations for students and students training \\
\hline & Expectations of Occupational therapy in Ghana. \\
\hline
\end{tabular}

